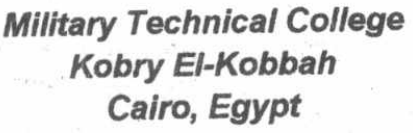

\title{
INVESTIGATION OF CHARACTERISTICS OF AN ELECTROHYDRAULIC SERVOACTUATOR INCORPORATING JET PIPE AMPLIFIER
}

\author{
A. A. El-Sayed ${ }^{1} \quad$ M. H. Gobran ${ }^{2} \quad$ M. Galal Rabie ${ }^{3} \quad$ M. R. Shalaan ${ }^{4}$
}

\begin{abstract}
This paper deals with the static and dynamic performance analysis of an electrohydraulic servoactuator (EHSA) used frequently in helicopter flight control systems. The investigated system is composed of a hydraulic actuator controlled by means of an electrohydraulic servovalve (EHSV). The servovalve includes a jet pipe hydraulic amplifier. The fluid flow characteristics of the jet pipe hydraulic amplifier are known to be extremely complex and do not lend themselves easily to theoretical analysis. Therefore, some published experimental data are used to predict the flow characteristics of this amplifier. A set of nonlinear simultaneous differential equations describing the dynamic behavior of the valve and actuator are derived. These differential equations are used to develop a MATLAB computer simulation program for the studied EHSA. To simplify the simulation, the EHSV model is replaced by a second order transfer function. The static characteristics of the EHSA and its basic elements are measured. The simulation results showed good agreement with the experimental results. The effects of supply pressure and internal leakage in the hydraulic cylinder on the transient response have been investigated theoretically.
\end{abstract}

Keywords: Electrohydraulic Servoactuator, Servovalve, Simulation, Jet pipe valve, Jet pipe amplifier.

\footnotetext{
${ }^{1}$ Egyptian Armed Forces.

2 Assistant Professor, Mechanical Power Dept., Zagazig University.

${ }^{3}$ Professor, Egyptian Armed Forces.

${ }^{4}$ Professor, Mechanical Power Dept., Zagazig University.
} 


\section{INTRODUCTION}

Electro-hydraulic servoactuators with jet pipe valve type are employed in many modern control applications including aircraft and missile control systems. Unfortunately the fluid flow characteristics inherent in jet pipe servo valve are extremely complex and do not lend themselves easily to any convenient form of theoretical analysis. Thus the valve is configured experimentally in a "cut and fit" manner and a suitable configuration is selected after many iterations.

In order to predict the jet pipe valve optimum configuration, a series of experiments had been be conducted, [1, $2 \& 3]$, where the valve performance was investigated for different geometric parameters, at various supply pressures. Some recommendations had been deduced regarding the valve geometric parameters that assure optimum performance in terms of pressure recovery, flow recovery and power transfer efficiency. In addition, Fomichev [3] deduced the relationship between the discharge coefficient and Reynolds number relationships for various nozzle types and dimensions.

Uppal [4] applied the estimation theory to the modeling problem of an electrohydraulic jet pipe valve. Some simplifying assumptions were made to achieve the simulation scheme. A reasonably accurate model for an EHSA with single stage jet pipe valve had been developed $[5,6]$, considering the system nonlinearly. Discharge coefficients of the orifices were estimated and verified until a high degree of correspondence between the performance of the model and that obtained from the real system.

The main objective of this study is to determine the steady state and transient behaviors of an EHSA incorporating jet pipe amplifier. The behavior is determined theoretically through deducing a mathematical model of EHSA, and simulating it using MATLAB computer program. Some published experimental results are used to deduce empirical formulae relating both nozzle and receivers discharge coefficients with the Reynolds number. The steady state and transient valve response are evaluated experimentally. The experimental results are used to evaluate the validity of the model and the simulation program.

\section{MODELING OF ELECTROHYDRAULIC SERVO ACTUATOR (EHSA)}

The investigated electrohydraulic servoactuator, shown in Fig. 1, consists of three main components: an electrohydraulic servovalve, a hydraulic cylinder and feedback elements. The electrohydraulic servo valve comprises two stages with mechanical feedback from the second stage. The first stage is of jet-pipe hydraulic amplifier type and the second stage is of spool type. The main components of the first stage are a torque motor, a jet nozzle, a feedback spring and two-hole receiver.

To develop the mathematical model, the following simplifying assumptions are considered:

i) Both oil temperature and viscosity are constant.

ii) The supply and return pressures are constants.

iii) The pressure losses in the valve and actuator inner lines are negligible compared with pressure losses in the valve restrictions.

iv) The material deformations are negligible. 


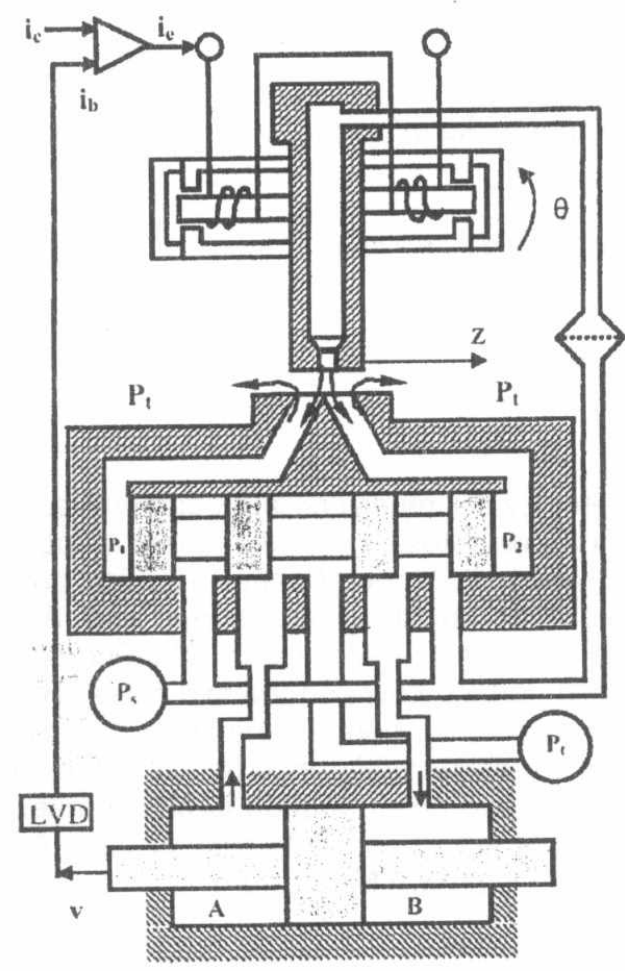

Fig. 1 Functional Scheme of the EHSA Excluding the feedback spring

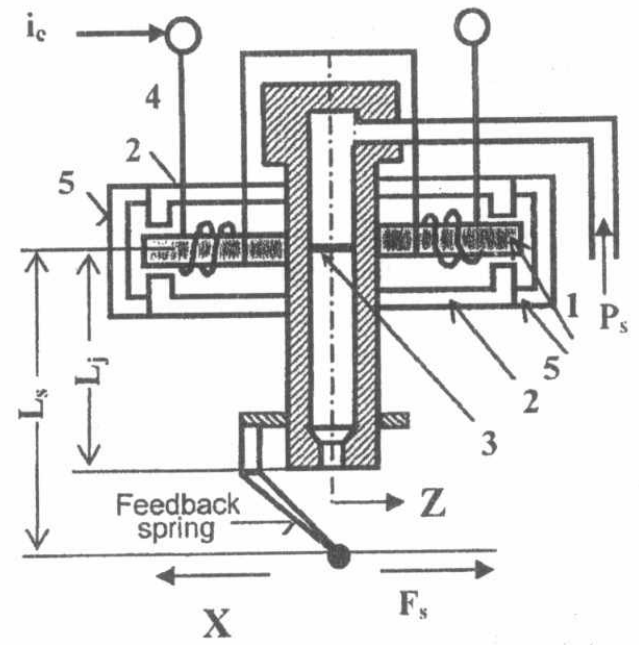

Fig. 2 Scheme of the torque motor

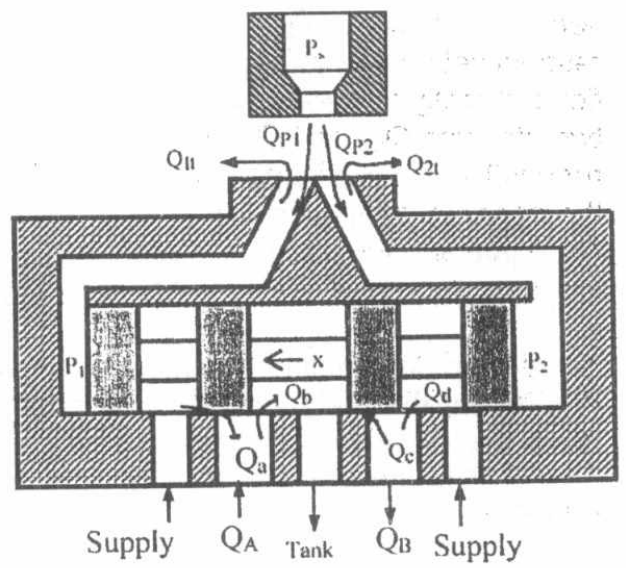

Fig. 3.Scheme of the JP amplifier

\subsection{Torque motor}

The torque motor converts the low-level electric input signal into a proportional mechanical torque, Fig. 2. It includes an armature (1) mounted on a torsional pin pivot spring (3) and suspended in the air gap of a magnetic field. The two polar pieces (2) form the framework around the armature and provide paths for the magnetic flux. When an electric current flows through the armature coils (4), a magnetic field is developed in the air gaps. Another field exists due do the permanent magnets (5). These two fields result in magnetic fields of different intensities in the air gaps leading to attraction forces between the polar pieces and the armature. The diagonally opposed gaps are symmetrical. A torque is thus produced on the armature. The torsion spring (3), or alternatively a flexible tube, causes the armature rotational angle to be proportional to the resulting torque. The motor torque $T$ depends mainly on the coil current $i_{e}$ and the armature angular displacement $\theta$. Neglecting the effect of the magnetic hysteresis; the following expression could be deduced, Appendix (A): 


$$
\mathrm{T}=\mathrm{K}_{\mathrm{i}} \mathrm{i}_{\mathrm{e}}+\mathrm{K}_{\theta} \theta
$$

The angular motion of armature and its attached parts is described by the following equation:

$$
T=J \frac{d^{2} \theta}{d t^{2}}+f_{\theta} \frac{d \theta}{d t}+K_{t} \theta+T_{s}
$$

where $\quad J=$ Moment of inertia of the rotating parts, $\mathrm{kg} \mathrm{m}^{2}$

$\mathrm{f}_{\theta}=$ Damping coefficient, $\mathrm{Nms} / \mathrm{rad}$

$\mathrm{K}_{\mathrm{t}}=$ Stiffness of torsional spring, $\mathrm{Nm} / \mathrm{rad}$

$T_{s}=$ Feedback sprig torque $=F_{s} L_{s}=\left(L_{s} \theta+x\right) K_{s} L_{s}, N m$

$L_{s}=$ Jet pipe length, $m$

$\mathrm{x}=$ Spool displacement, $\mathrm{m}$

$\mathrm{K}_{\mathrm{s}}=$ Stiffness of feedback spring, $\mathrm{N} / \mathrm{m}$

\subsection{Jet pipe amplifier}

Figure 3 shows a schematic drawing of the jet nozzle, receivers and spool valve. It indicates the main streams, pressures and flow rates. The fluid under supply pressure $p_{s}$, flowing from the jet nozzle, is divided into three streams. The first and second streams $Q_{p 1}$ and $Q_{p 2}$ pass through the throttling areas $A_{p 1}$ and $A_{p 2}$ respectively, into the two holes located side by side on the receiver. The third portion flows directly to the tank after colliding the solid surface between the two holes. The two streams $Q_{p 1}$ and $Q_{p 2}$ flow through paths in the sleeve body to chambers 1 and 2 respectively. The deflection of jet pipe creates a pressure difference $\left(p_{2}-p_{1}\right)$, forcing the spool to move. The fluid then flows out of the two holes through throttling areas $A_{1 t}$ and $A_{2 t}$, where the corresponding discharges are $Q_{1 t}$ and $Q_{2 t}$ respectively. An equivalent hydraulic circuit of the jet pipe amplifier is shown by Fig. 4 .

The jet pipe amplifier is described mathematically by six equations, four of which represent the discharge through each of the four-restriction areas shown in Fig. 4, and the other two represent the continuity through the two side chambers of the spool. The flow rates through the valve restrictions are given by the following equations.

$$
\begin{aligned}
& Q_{p 1}=C_{d p 1} A_{p 1}(z) \sqrt{\frac{2}{\rho}\left(p_{s}-p_{1}\right)} \\
& Q_{p 2}=C_{d p 2} A_{p 2}(z) \sqrt{\frac{2}{\rho}\left(p_{s}-p\right)} \\
& Q_{11}=C_{d 1 t} A_{11}(z) \sqrt{\frac{2}{\rho}\left(p_{1}-p_{t}\right)} \\
& Q_{2 t}=C_{d 2 t} A_{12}(z) \sqrt{\frac{2}{\rho}\left(p-p_{t}\right)}
\end{aligned}
$$

Neglecting the spool valve internal leakage, Fig. 3, then the application of continuity equation to the spool side chambers yields:

$$
Q_{p 1}-Q_{1 t}+A_{s} \frac{d x}{d t}-\frac{V_{10}-A_{s} x}{B} \frac{d p}{d t}=0
$$




$$
Q_{p}-Q_{2 t}-A_{s} \frac{d x}{d t}-\frac{V_{20}+A_{s} x}{B} \frac{d p}{d t}=0
$$

where $\quad V_{20}=$ Initial volume of left chamber, $\mathrm{m}^{3}$

$\mathrm{V}_{10}=$ Initial volume of right chamber, $\mathrm{m}^{3}$

$\mathrm{B}=$ Bulk modulus of oil, $\mathrm{Pa}$

$A_{s}=$ Spool side area, $m^{2}$

The throttling areas of the studied JP amplifier, nozzle discharge coefficient and receivers discharge coefficients are not defined, and must therefore be evaluated for the whole range of nozzle displacement. This is done as follows.

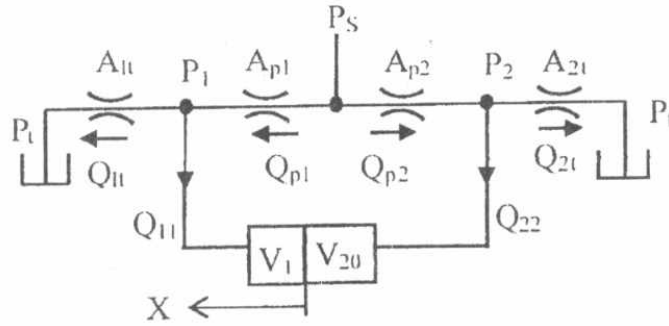

Fig. 4 Fluid flow through the JP amplifier

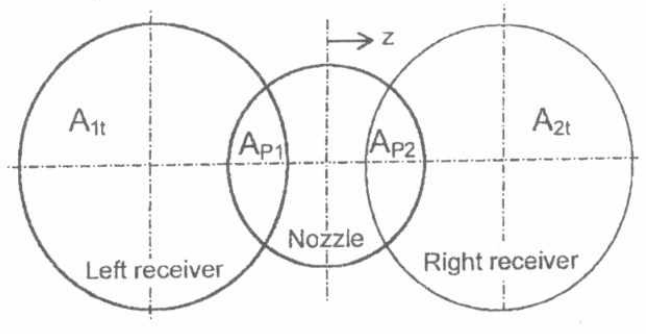

Fig. 5. Throttling areas of Jp amplifier
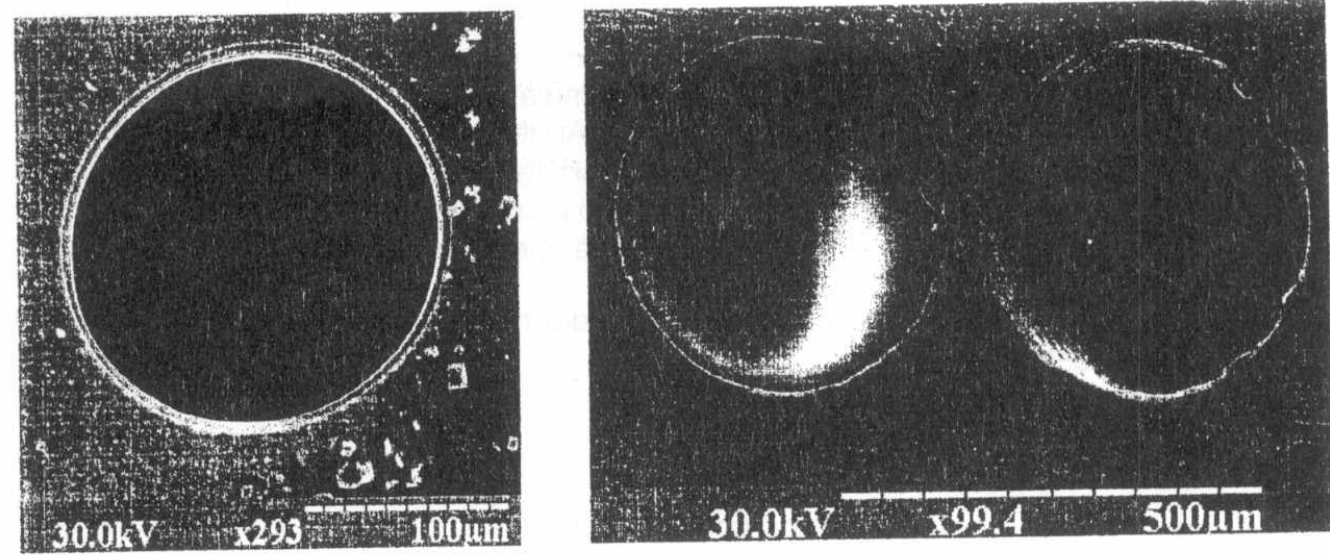

Fig. 6. Photo of jet nozzle and receivers, photographed by electron microscope, Department of Metallurgy, military technical College, Cairo.

The throttling areas in the flow path in the jet pipe amplifier include the annulus area between the jet end and the receivers face and also the areas generated by the intersection of the jet nozzle circle and the two receiver circles. The clearance separating the nozzle from the receiver face is $0.3 \mathrm{~mm}$. Therefore, the throttling areas in the flow path are the areas generated by the intersection between the jet nozzle circle and the two receiver circles, Figs. 5 and 6. The variation of these areas with nozzle displacement has been calculated and plotted in Fig. 7. 


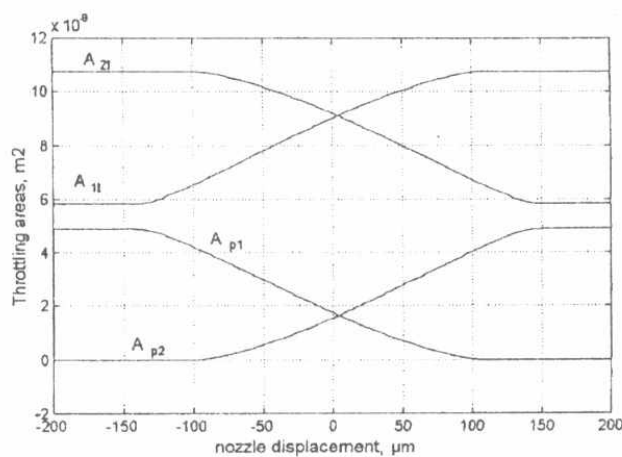

Fig. 7 Variation of JP amplifier areas with nozzle displacement.

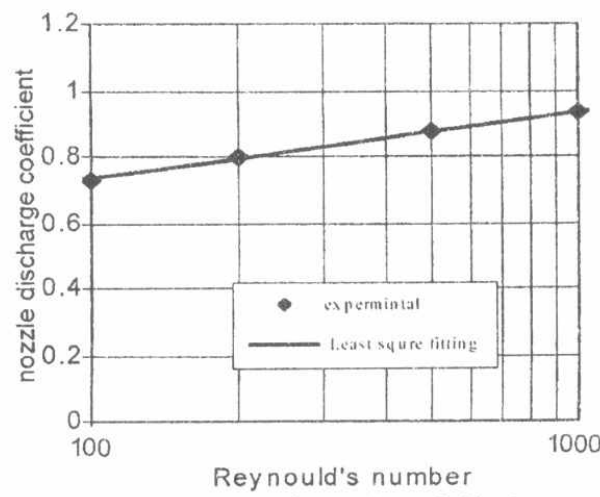

Fig. 8 Experimental results of discharge coefficient[3]

The discharge coefficient of cylindrical and conical nozzles $\left(C_{d p}\right)$ has been experimentally investigated by Fomichev [3]. The results are presented in appendix A, Fig. A1. A least square curve was fitted to these results, for the range of Reynolds number from 100 to 1000 , Fig. 8 . The obtained equation of the least square fitted curve is:

$$
C_{d p}=0.4543 \operatorname{Re}^{0.105} \text {. }
$$

The receivers discharge coefficients were predicted on the basis of Fomichev's experimental results, Fig. A4. A mathematical model was deduced for the JP amplifier and used to develop a computer simulation program. The geometric and operating data of Fomichev valve were used. An iterative process was carried out to find out the numerical values of receiver's discharge coefficient, giving the measured valve flow rate and pressure difference. This process was repeated at different nozzle displacements. The predicted discharge coefficient is plotted in Fig. 9.

Neglecting the jet momentum forces, the spool motion could be described by the following equation.

$$
A_{s}\left(p_{2}-p_{1}\right)=m_{s} \frac{d^{2} x}{d t^{2}}+f_{s} \frac{d x}{d t}+F_{s}
$$

where $\quad f_{s}=$ Spool-sleeve friction coefficient, $\mathrm{Ns} / \mathrm{m}$

$\mathrm{F}_{\mathrm{s}}=$ Feedback spring force, $\mathrm{N}$

$\mathrm{m}_{\mathrm{s}}=$ Spool mass, $\mathrm{kg}$

The flow rates through the zero-lapped valve throttling areas, Fig. 3, are given by:

$$
\begin{aligned}
& Q_{a}=C_{d} A_{a}(x) \sqrt{\frac{2}{\rho}\left(p_{s}-p_{A}\right)} \\
& Q_{b}=C_{d} A_{b}(x) \sqrt{\frac{2}{\rho}\left(p_{A}-p_{t}\right)} \\
& Q_{C}=C_{d} A_{C}(x) \sqrt{\frac{2}{\rho}\left(p_{B}-p_{A}\right)}
\end{aligned}
$$




$$
Q_{d}=C_{d} A_{d}(x) \sqrt{\frac{2}{\rho}\left(p_{s}-p_{B}\right)}
$$

The spool valve throttling areas, Fig. 1, are calculated by using the following equations.

$$
\begin{aligned}
& A_{a}(x)=A_{c}(x)=\left\{\begin{array}{cc}
A_{r} & x>0 \\
b|x|+A_{r} & x \leq 0
\end{array}\right. \\
& A_{b}(x)=A_{d}(x)=\left\{\begin{array}{cc}
b x+A_{r} & x>0 \\
A_{r} & x \leq 0
\end{array}\right. \\
& A_{r}=\pi c D_{S}
\end{aligned}
$$

where $\quad b=$ Width of the flow passage slot on the spool, $m$

$\mathrm{c}=$ Spool radial clearance, $\mathrm{m}$

$D_{\mathrm{s}}=$ Spool diameter, $\mathrm{m}$

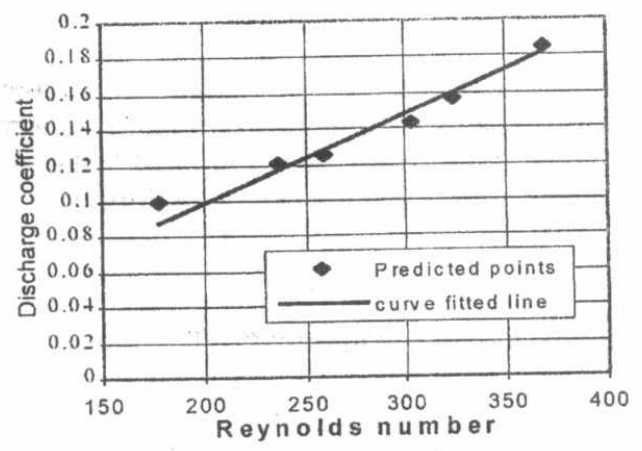

Fig. 9 The predicted receivers discharge coefficient

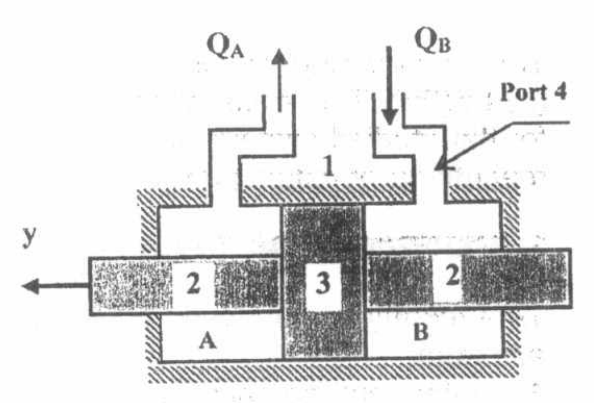

Fig. 10 Symmetrical hydraulic cylinder

\section{Mathematical Model of the Cylinder}

Neglecting the external leakage, the equations governing the behavior of the symmetrical hydraulic cylinder, Fig. 10, are as follows:

$$
\begin{aligned}
& Q_{B}-A_{P} \frac{d y}{d t}-\frac{p_{B}-p_{A}}{R}-\frac{V_{B 0}+A_{P} y}{B} \frac{d p_{B}}{d t}=0 \\
& A_{D} \frac{d y}{d t}-Q_{A}+\frac{p_{B}-p_{A}}{R}-\frac{V_{A 0}-A_{P} y}{B} \frac{d p_{A}}{d t}=0
\end{aligned}
$$

where $V_{A 0}=$ Initial volume of chamber $A, m^{3}$

$V_{B 0}=$ Initial volume of chamber $B, \mathrm{~m}^{3}$

$\mathrm{R}=$ Resistance to internal leakage, $\mathrm{Pas} / \mathrm{m}^{3}$

$\mathrm{y}=$ Spool displacement, $\mathrm{kg}$

Regarding to Fig. 3, the flow rates $Q_{A}$ and $Q_{B}$ can be expressed as: 


$$
\begin{aligned}
& Q_{A}=Q_{b}-Q_{a} \\
& Q_{B}=Q_{d}-Q_{C} \\
& A_{p}\left(P_{A}-P_{B}\right)=m_{p} \frac{d^{2} y}{d t^{2}}+f_{p} \frac{d y}{d t}+K_{p} y
\end{aligned}
$$

where $\quad A_{p}=$ Piston side area, $m^{2}$ $m_{p}=$ mass of the piston, $\mathrm{kg}$

$f_{p}=$ Friction coefficient of the piston, $\mathrm{Ns} / \mathrm{m}$

$\mathrm{K}_{\mathrm{p}}=$ Equivalent loading stiffness, $\mathrm{N} / \mathrm{m}$

\subsection{Feedback}

The piston displacement is picked-up using an LVDT and fed back to an electronic controller which generates the corresponding error signal. This is described by the following equations,

$$
\begin{aligned}
& \mathrm{i}_{\mathrm{e}}=\mathrm{i}_{\mathrm{c}}-\mathrm{i}_{\mathrm{b}} \\
& \mathrm{i}_{\mathrm{b}}=\mathrm{K}_{\mathrm{b}} \mathrm{y}
\end{aligned}
$$

The studied electrohydraulic servosystem is described mathematically by equations (1) to (25). These equations were used to develop a computer simulation program for the studied system. The numerical data of the system were found partially in the manufacturer catalogues and by direct measurernents on the actual elements.

\section{EXPERIMENTAL INVESTIGATION}

The experimental work conducted on the studied electrohydraulic servosystem aimed at:

1. Finding out the basic constructional and operational parameters characterizing the studied system, such as the spool radial clearance.

2. Measuring the steady state and transient system characteristics needed to evaluate the validity of the developed simulation program; namely:

a- the steady state amplifier pressure gain, $\Delta p=p_{2}-p_{1}$, against the jet nozzle displacement $z$.

b- the steady state piston displacement against the control current, y(i).

c- the transient response of piston displacement for step input current.

\subsubsection{Spool radial clearance and friction coefficient}

The actual spool radial clearance is predicted experimentally by measuring the spool radial clearance leakage. The experiment was conducted by blocking the hydraulic supply line to the hydraulic jet pipe valve and measuring the spool valve leakage $\left(Q_{1}\right)$. The flow rate is measured using a volume meter and stop watch. The radial clearance is formed to be reasonably predicted using the following relation [8]:

$$
\Delta p=\frac{12 \mu L}{\pi D C^{3}} Q_{L}+\sum \zeta \frac{\rho}{2} \frac{Q_{L}{ }^{2}}{(\pi D C)^{2}}
$$


where $\Delta p=$ Pressure difference between the supply and leakage outlet, $\left(\Delta \mathrm{p}=\mathrm{p}_{\mathrm{s}}-\mathrm{p}_{\mathrm{atm}}\right)$; which is the supply gauge pressure

The viscous friction coefficient of the spool is calculated by the following equation:

$$
\mathrm{f}_{\mathrm{s}}=\frac{\pi \mu \mathrm{DL}}{\mathrm{C}}
$$

where $\quad L=$ Total length of spool lands, $m$

$\mathrm{C}=$ Spool radial clearance, $\mathrm{m}$

$\rho=$ Oil density, $\mathrm{kg} / \mathrm{m}^{3}$

$\mu=$ Dynamic viscosity, Pa s

$Q_{L}=$ Leakage flow rate, $\mathrm{m}^{3}$

\subsubsection{JP steady state performance, $\Delta p(z)$}

The measurement of valve pressure gain was conducted by connecting two calibrated pressure gages to both receiver chambers. The control current is present at different values at open loop connection. The corresponding nozzle displacement is calculated considering the linear relation between the armature displacement and the control current. The experiment is conducted at a supply pressure of 105 bar and zero return pressure. The experimental results are plotted in Fig. 11.

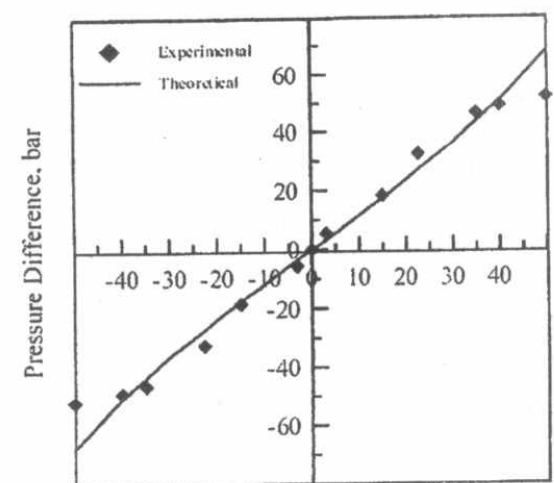

Nozzle Displacement, $\mu \mathrm{m}$

Fig. $11 \mathrm{JP}$ amplifier pressure gain

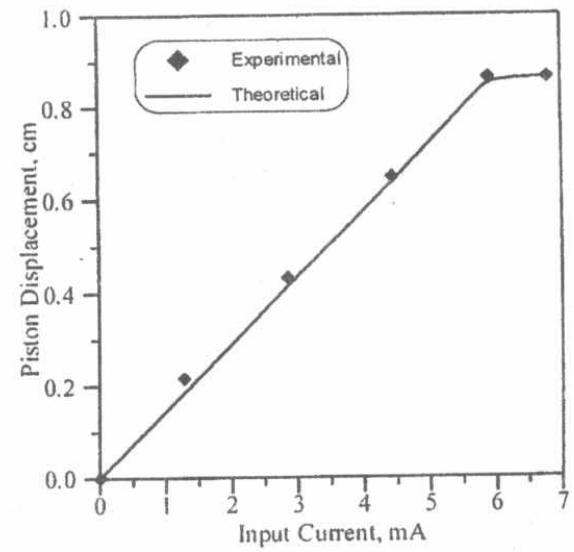

Fig. 12 Steady state piston displacement Versus input current, closed loop case

\subsubsection{EHSA steady state displacement, y (i)}

The steady state piston displacement was measured for different magnitudes of control current in closed loop arrangement. The results are shown in Fig.12.

\subsubsection{EHSA transient response}

The transient variation of the piston displacement of EHSA is measured for step input control current of different magnitudes. The measurements were carried out for 
the closed loop case, at supply pressure of 105 bar and zero return pressure. Figure 13 shows the measured step response for $6 \mathrm{~mA}$ step current.

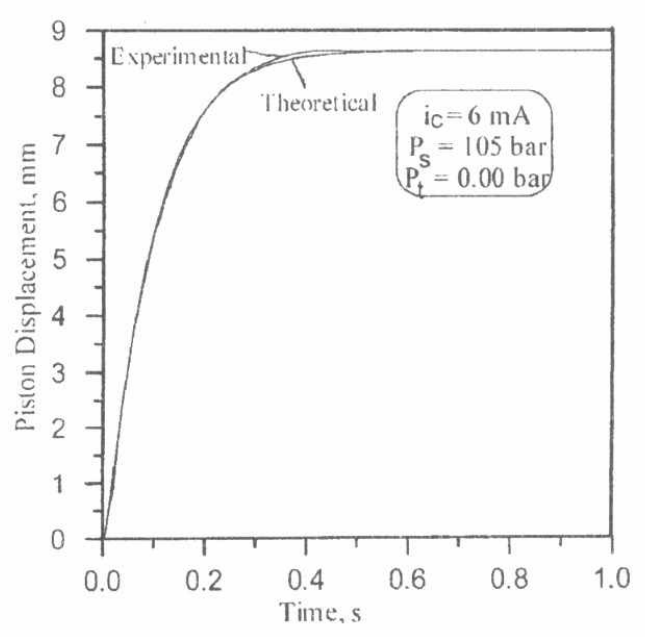

Fig.13 Step response of the EHSA

\section{RESULTS AND ANLYSIS}

\subsection{Validity of the Simulation Program}

The steady state pressure difference in the amplifier receiver chambers $\left(p_{2}-p_{1}\right)$, was calculated using the simulation program. The supply and return pressures were set at 105 and zero bar respectively. The simulation results are plotted in Fig. 11, which shows good agreement between theoretical and experimental results in the range $z= \pm 40 \mu \mathrm{m}$. For jet displacements beyond this range, the simulation program gives a higher pressure difference compared to experimental. This result indicates that the simulation program is reliable in the practical range of operation of the tested EHSA. The difference at the higher range could be attributed to the fact that the predicted receivers discharge coefficient is based on experimental work carried out for smaller nozzle displacement range.

The steady state dependence of the EHSA displacement on the control current was calculated using the simulation program and plotted in Fig. 12 for control input current up to $7 \mathrm{~mA}$ in closed loop arrangement. This figure shows good agreement between the theoretical and experimental results in the whole operating range of the EHSA. The EHSA presents linear displacement- current relation up to about $6 \mathrm{~mA}$.

The transient response of the EHSA piston displacement to step control current of different magnitudes was calculated. Figure 13 shows the response for a $6 \mathrm{~mA}$ step current, at supply and return pressures of 105 and zero bar respectively. This figure shows that the steady state values are identical, while the simulation program presents quite slightly slower response compared with the experimental results. This might be attributed mainly to the friction coefficient in the cylinder. This coefficient is highly affected by the degree of squeezing of the oil seals at higher pressures and their actual state. 


\subsection{Representative Model of the Servovalve}

The step response of the EHSV was calculated for different magnitudes of input current steps. The normalized response is plotted in Fig. 14, where $\bar{x}=x(t) / x_{\text {ss }}$. This figure shows that the normalized responses are practically coincident. This coincidence indicates the linearity of the behavior of the EHSV. The step response is apparently similar to that of an over damped second order system. Therefore it can be represented by the following transfer function:

$$
G(s)=\frac{X}{I_{e}}(s)=\frac{k \omega_{n}^{2}}{s^{2}+2 \xi \omega_{n} s+\omega_{n}^{2}}
$$

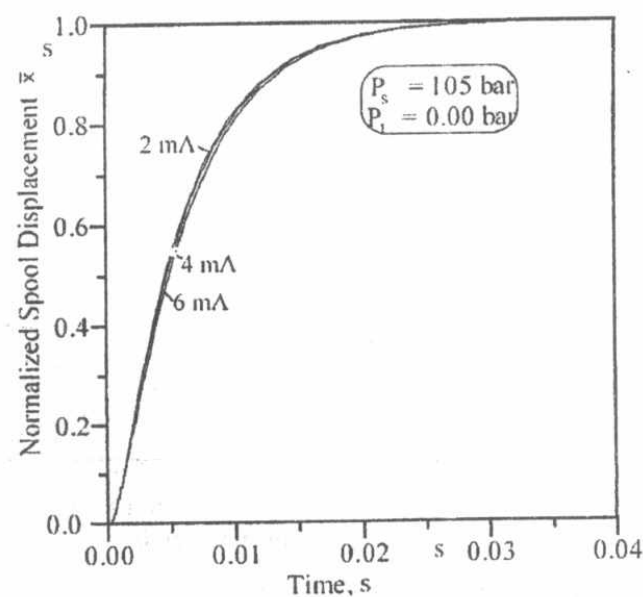

Fig. 14 calculated step response of servovalve

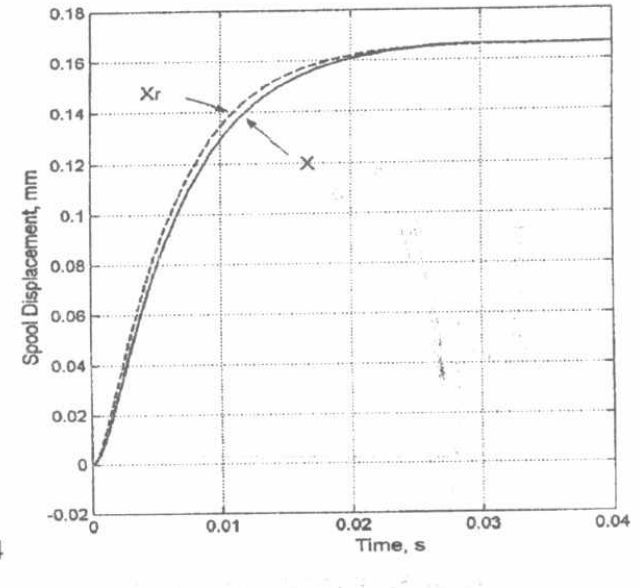

Fig.15 Step response EHSV simulation program $\mathbf{x}$ and representative model $\mathbf{x}_{\mathbf{r}}$

The parameters of the transfer function were found to be; $k=0.028 \mathrm{~A} / \mathrm{m}, \omega_{\mathrm{n}}=360$ $\mathrm{rad} / \mathrm{s}$ and $\xi=1.3$. The transient response of the spool displacement for a $6 \mathrm{~mA}$ step current was calculated by using the detailed model and representative models. The simulation results are plotted in Fig. 15. This Figure shows good agreement between the response obtained from the detailed and representative models. Therefore, the transfer function given by equation (28) is used in the further investigations to simplify the simulation program.

\subsection{Effect of Some Constructional and Operational Parameters on the Step Response of EHSA}

The validated simulation program is used for the further investigations of the effect of constructional and operational parameters. Herein, the effects of supply pressure and internal leakage on the dynamic behavior of the EHSA are investigated. 


\subsubsection{Effect of supply pressure}

The transient response of EHSA was calculated for different values of the supply pressure, keeping zero return pressure, for $6 \mathrm{~mA}$ step current. The obtained results are presented in Fig. 16.

The settling, delay and rise times are given in Fig. 17. This figure shows that the reduction in supply pressure leads to considerable delay in the response. Therefore, the required speed of response becomes one of the main factors determining the operating pressure. In the case of the studied EHSA, the supply pressure is limited to 85 bars.

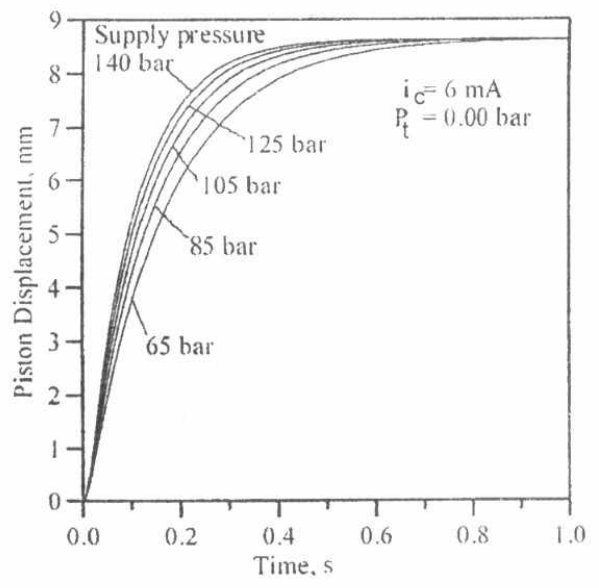

Fig.16 EHSA step response for different supply pressure levels

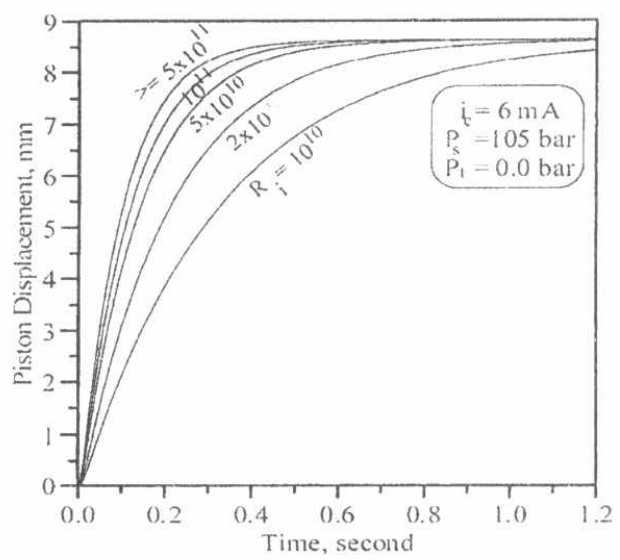

Fig.18 EHSA step response for different values of internal leakage resistance

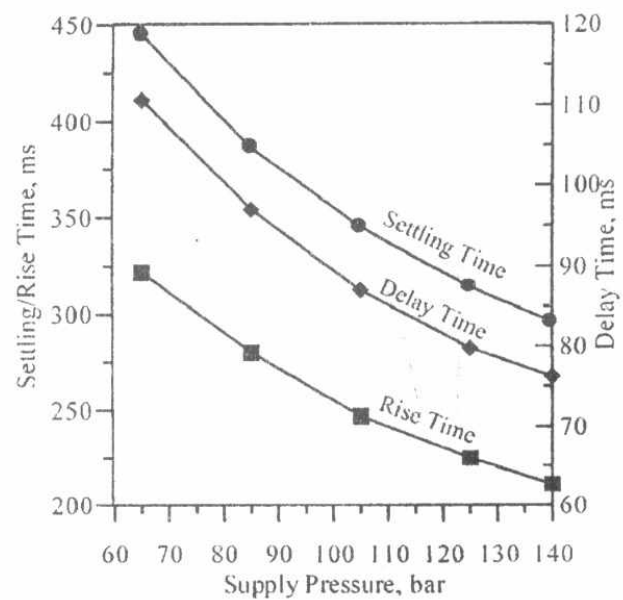

Fig.17 Effect of supply pressure on the settling ad delay times

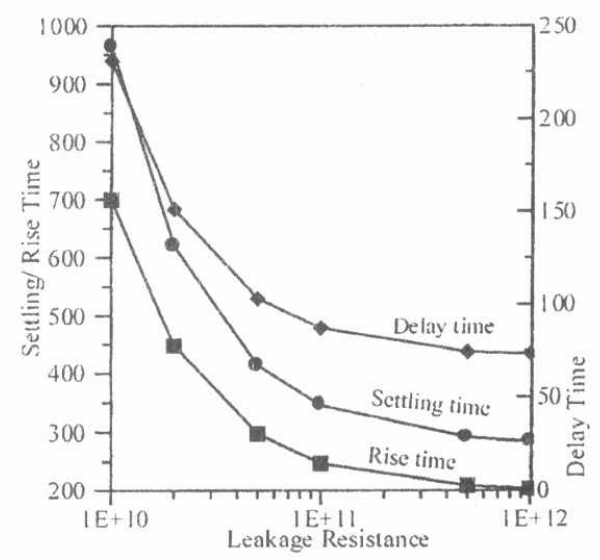

Fig.19 Effect of inner leakage résistance on settling ad delay times 


\subsubsection{Effect of cylinder internal leakage resistance}

The transient response of EHSA was calculated for different values of cylinder internal leakage resistance, keeping zero return pressure, 105 bar supply pressure and $6 \mathrm{~mA}$ step current input. The calculated results are given in Fig. 18. These results show that the reduction of leakage resistance introduces considerable steady state error. This steady state error could be avoided by replacing the proportional feedback arrangement by a more advanced controller such as the pseudo-derivative feedback system. The settling, delay and rise times of the transient response are given in Fig.18. This figure shows that the increase of leakage resistance decreases these times, i.e. the response becomes faster. For values greater than $5 \times 10^{11}$ $\mathrm{Pa} . \mathrm{s} / \mathrm{m}^{3}$, no more improvement is observed. This resistance corresponds to an internal leakage of $0.6 \mathrm{lit} / \mathrm{min}$ for 50 bar pressure difference.

\section{CONCLUSIONS}

This work was directed to investigate the steady state and dynamic behavior of the EHSA used in many applications, such as in the stability and control system of a helicopter. The studied EHSA has a jet pipe amplifier. The EHSA was investigated theoretically and experimentally. The theoretical study included the deduction of a nonlinear mathematical model and development of a computer simulation program. The complexity of the fluid flow characteristics in the JP servovalve was overcome by deducing an empirical formula for the nozzle and receivers' discharge coefficients based on published experimental results.

The steady state and transient characteristics of the EHSA and its basic elements were measured. The simulation results were found to be in good agreement with the experimental results, which validates the developed simulation programs. The theoretical analysis of EHSV was simplified by developing a simple transfer function describing the servovalve behavior.

The investigation of the EHSA performance showed that:

(1) The developed detailed simulation program represents the dynamic behavior of the studied electrohydraulic servo-actuator with acceptable precision. The procedure followed for the analysis of the used jet pipe amplifier was shown to be efficient. The model was simplified by describing the studied servovalve by a second order transfer function of $360 \mathrm{rad} / \mathrm{s}$ natural frequency, 1.3 damping coefficient and 0.028 gain.

(2) The reduction of supply pressure has significant effect on decreasing the speed of response of the EHSA. Thus, a limitation of minimum supply pressure is imposed by both of the required driving force and the transient response requirements.

(3) The increase in internal leakage leads to considerable increase of the settling, delay and rise times. It introduces observable steady state error. This adverse effect of internal leakage can be avoided by the proper choice of the EHSA controller. The increase of leakage resistance decreases the settling, delay and rise times of the transient response. No more improvement of the transient response is observed for values greater than $5 \times 10^{11} \mathrm{Pas} / \mathrm{m}^{3}$. 


\section{REFERENCES}

[1] Alpay, S. A., "Design and Performance Characteristics of a Hydraulic Jet-pipe Valve", Proceedings of $9^{\text {th }}$ Int. American Automatic Control Conference, Univ. of Michigan, Ann Arbor, MI., June. 26-28, 1968, pp 88-101

[2] Kirk, M. F. Lichtarowicz, A. and Pearce, I. D., "Characteristics of jet-pipe valves" British Hydro-mechanics Research Assn., $4^{\text {th }}$ Cranfield Fluidics Conference, Univ. Of Warwick, Coventry, England, Volume 1. Marsh. 17-20, 1970. pp B5-69 to $\mathrm{B} 5-87$.

[3] Fomichev V. M., "Form of Channels and the Structure of Flows in HighPressure Hydraulics Amplifiers of the Jet Pipe Type", Soviet Engineering Research vol. 3, n 10, pp 18-21, ISSN:0144-6622,Oct 1983.

[4] Uppal, S. Y. and Thompson, K. C. "Parameter Estimation of Electro-Hydraulic Single Stage Jet Pipe Valve" In: Guidance and Control Conference, Palo Alto, Calif., August 7-9, 1978. New York, AIAA, Inc. p. 407-412, 1978.

[5] T. W. McLain, E.K. Iverson, C. C. Davis and S. C. Jacobsen "Development ,Simulation, and Validation of a high nonlinear servo-system model" American control conference, pp: 385-391, pittsbergh, Pennsylvania, June 21-23, 1989

[6] Glen Bilodeau and Evangelos Papadopoulos, "Development of a Hydraulic Manipulator Servo-actuator Model Simulation and Experimental Validation" Center for Intelligent Machines, McGill University, Montreal, Canada, 1997.

[7] Fadel M. A., Krutz G and White H., "Dynamic Behavior of Servo Control Systems Utilizing an EASY5 Hydraulic System Model", The Sixth Scandinavian International Conference on Fluid Power, SICFP'99, Tampere, Finland, May 2628, 1999.

[8] MOOG Technical Bulletin No.117, Specification Standards for Electro-Hydraulic Flow Control Servo-Valves.

[9] El-Sayed A. A., An Investigation of the Dynamic Behavior of a Helicopter Electro-hydraulic Servo-Actuator, M.Sc. Thesis, Faculty of Engineering, Zagazig University, 2002.

\section{APPENDIX A}

The available literature does not include any theoretical technique to analyze the jet pipe hydraulic amplifiers. Therefore, herein, an effort is paid to solve this problem. The solution is based on the experimental results published by Fomichev [3], for a similar JP amplifier. Figure A1 shows the layout of the jet pipe amplifier while Fig. A2 shows the test arrangement. The work of Fomichev included the dimensions, experiment conditions and the results shown by Figs $\mathrm{A} 3$ and $\mathrm{A} 4$. Figure $\mathrm{A} 3$ was used to deduce an empirical relation for the nozzle discharge coefficient for the practical range of Reynolds number.

The experimental results of the flow rate and pressure characteristics, Fig. A4, were used to deduce a relation between the discharge coefficient of receiver holes and Reynolds number. This process was carried out as follows:

(1) A mathematical model was deduced for the JP amplifier, connected as shown by Fig. A2. The mathematical model consists of the following equations: 

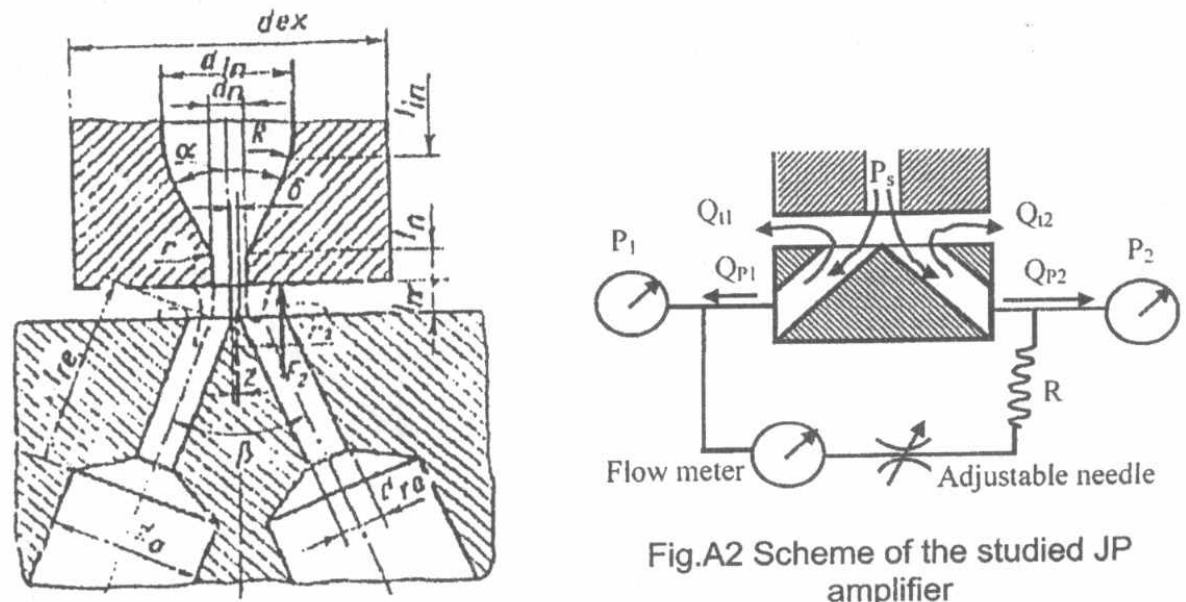

Fig.A2 Scheme of the studied JP amplifier

Fig.A1 Fomichev's cylindrical JP amplifier

$$
\begin{aligned}
& Q_{p 1}=C_{d p 1} A_{p 1}(z) \sqrt{\frac{2}{\rho}\left(p_{s}-p_{1}\right)} \\
& Q_{p 2}=C_{d p 2} A_{p 2}(z) \sqrt{\frac{2}{\rho}\left(p_{s}-p_{2}\right)} \\
& Q_{1 t}=C_{d 1 t} A_{1 t}(z) \sqrt{\frac{2}{\rho}\left(p_{1}-p_{t}\right)} \\
& Q_{21}=C_{d 2 t} A_{2 t}(z) \sqrt{\frac{2}{\rho}\left(p_{2}-p_{t}\right)} \\
& Q_{p 1}-Q_{11}+Q_{12}-\frac{V_{10}}{B} \frac{d p_{1}}{d t}=0 \\
& Q_{p}-Q_{1}-Q_{12}-\frac{V_{20}}{B} \frac{d p}{d t}=0 \\
& Q_{21}=\frac{p_{2}-p_{1}}{R} \\
& R e=\frac{\rho v D_{c}}{\mu}
\end{aligned}
$$

where the wet diameter $D_{C}=(4 x$ Flow area $) /$ Wet perimeter

(2) Two simulation programs were developed based on equations $A 1$ to $A 8$ for two different cases:

- Needle fully closed; pressure recovery characteristics.

- Needle fully open; flow recovery characteristics

(3) Both programs were used simultaneously in iterative process for different nozzle displacements to predict the value of receivers discharge coefficients.

(4) The obtained discharge coefficient-Reynolds number relation is shown in Fig.9. 


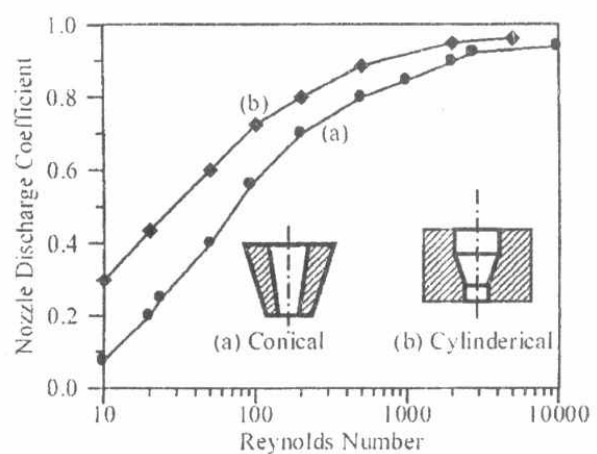

Fig.A3 Discharge coefficient of conical and cylindrical orifices.

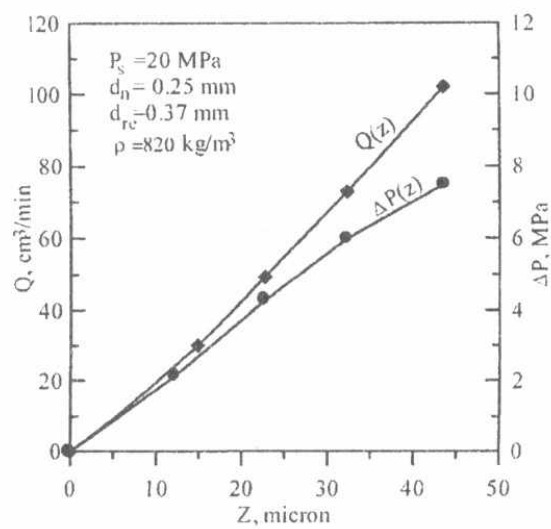

Fig.A4 Steady state flow rate and pressure characteristics of JP amplifier 


\section{NOMENCLATURE}

$C_{f} \quad$ skin-friction coefficient

F constant shift in the velocity profiles in wall coordinates, $F=-\Delta U / U_{\tau}$

$\mathrm{h}$ groove or riblet height

$\mathrm{h}^{+} \quad$ groove or riblet height in wall units, $\equiv \mathrm{hU}_{\boldsymbol{\tau}} / v$

k turbulent kinetic energy

L length of the test plate

1 length scale of energy containing eddies

p pressure

Re Reynolds number

s groove or riblet spacing

$\mathrm{s}^{+} \quad$ groove or riblet spacing wall units, $\equiv \mathrm{SU}_{\tau} / \mathrm{v}$

St Stanton number

Tu free-stream turbulence intensity

$U$ mean velocity in $x$ direction

$U_{0} \quad$ free-stream mean velocity

$\mathrm{U}_{\tau} \quad$ friction velocity

$\mathrm{u}^{+} \quad$ non-dimensional velocity, $\equiv \mathrm{U} / \mathrm{U}_{\tau}$

$u_{\text {ms }} \quad$ root mean square value of stream-wise velocity fluctuations

$\mathrm{V}$ mean transverse velocity

$x \quad$ stream-wise distance from beginning of the working section

$x_{\text {ref }}$ distance from beginning of the working section to leading edge of test plate

y co-ordinate normal to wall

$\mathrm{y}^{+} \quad$ non-dimensional distance from the wall, $\equiv \mathrm{yU}_{\tau} / \mathrm{v}$

$\delta \quad$ boundary layer thickness

$\delta^{*} \quad$ displacement thickness.

$\theta \quad$ momentum thickness

$\varepsilon \quad$ rate of dissipation of turbulent kinetic energy

$\kappa \quad$ Von Karman constant

$\mu \quad$ dynamic viscosity

$v \quad$ kinematic viscosity

$v_{t} \quad$ turbulent kinematic viscosity

$\rho$ density

$\tau_{w} \quad$ wall shear stress

\section{INTRODUCTION}

In recent years, turbulent boundary layer drag reduction has become an important area of fluid dynamics research. Rising fuel costs in the 1970 s greatly emphasized the usefulness and necessity of developing efficient viscous drag reduction methods. Many classes of transport and other important application stand to reap great rewards from the successful application of viscous drag reduction techniques. Some examples are: commercial transport aircraft, high-speed aircraft and missiles, surface ships that operate at low Froued number, submarines and other underwater 